\title{
Gaudium et spes - La alteración de un orden lógico y teológico Debates en el cuarto período (1965) del Vaticano II
}

\author{
CARLOS SCHICKENDANTZ \\ Centro Teológico Manuel Larraín \\ Universidad Alberto Hurtado \\ iDhttps:/ / orcid.org/0000-0003-3897-80
}

\begin{abstract}
Resumen: Aunque no pudieran explicar su naturaleza exacta, la mayoría de los participantes en el Vaticano II advirtieron la innovación metodológica que estaba en juego en Gaudium et spes. El artículo se concentra en las discusiones en el aula conciliar - en los meses de septiembre y octubre de 1965- en las que se presentaron aproximadamente 550 intervenciones, orales y escritas. Que el debate conciliar bajo esta perspectiva se focalizara en el título de la Constitución, es fácilmente explicable: "Nadie había oído (hablar) nunca de una constitutio pastoralis" (Borgman). La transformación del "orden lógico y teológico" existente (Congar), que se condensa en el título introducido en el esquema en abril de 1965, forma parte esencial de la inauguración oficial de una "Iglesia mundial" (Rahner), poscolonial, que reconoce una renovada significación al contexto cultural, geográfica y temporalmente situado.
\end{abstract}

Palabras clave: Constitución pastoral, ver-juzgar-obrar, Schema XIII

Abstract: Although they could not explain the exact nature of the methodological novelty at stake in Gaudium et spes, most participants of the Council realized it. This article focuses on discussions in the Conciliar Aula in the months of September and October of 1965, when approximately 550 oral and written interventions were presented. From this perspective, the debate was focused on the title of the Constitution: "no one had ever heard of a constitutio pastoralis" (Borgman). The transformation of the existing "logical and theological order" (Congar) summarized in the title introduced in the scheme in April 1965-became an essential part of the official beginning of a postcolonial "world Church" (Rahner) that recognized a renewed significance to the cultural, geographical, and temporal context.

Keywords: Pastoral Constitution, see-judge-act, Schema XIII 


\section{INTRODUCCION $^{1}$}

En su diario del Concilio Yves Congar registra un diálogo del 11 de octubre de 1965 cuando, concluido el debate en el aula conciliar sobre el esquema de la Constitución pastoral -presentado el 21 de septiembre-, comenzaba el trabajo de corrección conforme a las sugerencias recibidas. En relación al tema específico del ateísmo y del capítulo primero de la primera parte, ante la objeción de algunos, Congar escribe lo siguiente: "Ménager: los redactores siguieron un orden pedagógico, desde lo más conocido hasta lo menos conocido". Jacques Ménager -entonces obispo de Meaux, Francia- que en diciembre de 1964 había sido una figura clave, defiende allí el enfoque del esquema. Congar añade en su texto manifestando su propia opinión: "De hecho, las críticas que se podrían hacer muy legítimamente sobre la base de un orden lógico y TEOLÓGICO chocan con la intención de los redactores de seguir un orden fenomenológico"2. Es interesante la observación del teólogo francés porque indica claramente que, a su juicio, hay una "crítica legítima" al documento desde un punto de vista que da por supuesto: "un orden lógico y teológico" rivaliza con "seguir un orden fenomenológico". El asunto no parece que pueda caracterizarse más nítidamente. Es verdad que, por una parte, el latín del esquema no ayudaba: “iiiCuán espantoso es el latín del esquema XIII!!!”, exclama Congar de manera semejante a muchos padres conciliares en esas semanas. Por otra parte, el mismo lenguaje estaba necesitado de mayor precisión, sin duda. "Rahner, a quien el texto no le agrada, lo irrita, se sumó a las dificultades planteadas. Ve aproximaciones y expresiones informales en todas partes" . Pero esas limitaciones lingüísticas o conceptuales no opacan la afirmación de Congar: el orden fenomenológico rivaliza con un orden lógico y teológico. El hecho merece destacarse: uno de los mejores teólogos del momento -el dominico francés- percibe un cambio de "lógica", una variación en la forma de argumentar y presentar la fe en la metodología teológica, pero en un sentido la desacredita.

Estas breves referencias, que podrían multiplicarse citando otros teólogos del momento, testimonian con claridad una modificación en la forma de proceder en la argumentación de la fe de difícil conceptualización para varias de las mejores mentes de entonces; transformación de la que, a diversos niveles, también eran conscientes los padres conciliares.

En fecha reciente he publicado un artículo referido a los debates de los meses de octubre y noviembre de 1964, cuando la asamblea conciliar, por

\footnotetext{
${ }^{1}$ Este texto se enmarca en el proyecto de investigación Fondecyt № 1190556.

2 Y. CONGAR, Mon Journal du Concile (Cerf, Paris 2002) II, 430. Mayúscula del original.

${ }^{3}$ Y. CONGAR, Mon Journal du Concile, II, 431.
} 
primera vez, abordó un esquema global del entonces llamado Schema XIII ${ }^{4}$. El presente artículo se concentra exclusivamente en las discusiones en el aula conciliar del esquema presentado el 21 de septiembre de 1965 -congregación general 132 (AS IV , 1, 435-516)- que se extendieron hasta el día 8 de octubre -congregación general 145- ${ }^{5}$. Se cuentan aproximadamente 550 intervenciones orales y escritas que, no pocas veces, incluyen la adhesión de varios padres conciliares. Alrededor de 80 de ellas pertenecen a obispos latinoamericanos y caribeños o, en mucho menor caso, a textos de obispos de otros continentes a los cuales ellos adhieren. La utilidad de prestar atención a las intervenciones de los padres conciliares $-\mathrm{y}$ no solo a los textos oficiales con sus respectivos informes de presentación- reside en la variedad de matices que se advierte; permite pulsar mejor el sentir de la asamblea, ayuda a encontrar frases muy precisas, a percibir las expresiones repetidas, a medir mejor los consensos, a descubrir las perplejidades y aquilatar las oposiciones. Este artículo se limita a considerar -además de algunos juicios globales sobre el documento- solo los aspectos referidos al título, la forma de proceder, la metodología, la estructura y los destinatarios del esquema, el género literario o estilo. Se trata de aspectos directamente vinculados con la transformación del "orden lógico y teológico" que advierte Congar. Que el debate conciliar en esos meses se focalizara en el título de la Constitución, que en buena medida condensa esa innovación, es bien explicable: "Nadie había oído nunca (hablar) de una constitutio pastoralis".

Después de los debates de fines de septiembre e inicios de octubre de 1965 el itinerario redaccional del documento tuvo dos momentos clave en el aula conciliar: la presentación del renovado esquema el 15 de noviembre de 1965 congregación general 161- del llamado Textus recognitus (AS IV, 6, 421-560) y el 2 de diciembre -congregación general 166- del texto definitivo, llamado Texto denuo recognitus (AS IV , 7, 234-314), que incluía la importante información sobre la Expensio modorum (AS IV, 7, 347-610). Esta fase redaccional final no está analizada en esta contribución.

\footnotetext{
${ }^{4}$ Cf. C. SCHICKENDANTZ, "Un género literario y teológico en formación. Debates en la historia de la redacción de Gaudium et spes", Teología 133 (2020) 183-215.

5 Acta Synodalia Sacrosancti Concilii Oecumenici Vaticani II, Typis Polyglottis Vaticanis, 1970ss.; en adelante AS; se cita primero el volumen, luego, la parte y, finalmente, la página.

6 E. Borgman, "Gaudium et Spes: el futuro olvidado de un documento revolucionario", Concilium 312 (2005) 59-68, 59.
} 


\section{El CAMINO HACIA LOS DEBATES EN EL CUARTO PERÍODO CONCILIAR}

Después de las congregaciones generales en los meses de octubre y noviembre de 1964 en las cuales se debatió un texto completo del Schema XIII, la Subcommissione plenaria mixta responsable del esquema tomó varias decisiones para concretar el proceso de corrección a partir de las propuestas de los padres conciliares. Se amplió el número de obispos pertenecientes a diversas regiones y continentes de una manera representativa, y se aprobó la necesidad de ampliar el "conspectus generalis (olim signa temporum)" que presentaba las características principales del mundo contemporáneo como punto de inicio de todo el esquema. Dos decisiones importantes guiaron los siguientes pasos: el texto presentado a la asamblea en octubre de 1964 se consideró como base sobre la cual se harían las mejoras solicitadas y, segundo, los adnexa fueron incorporados al texto del documento como una segunda parte (AS IV, 1, 518-519).

El trabajo más importante sobre el texto se desarrolló en Ariccia, cerca de Roma, entre el 31 de enero y el 6 de febrero de 1965. Participaron 29 obispos, 38 peritos y unos 20 auditores/as laicos/as. Posteriormente -en una reunión de febrero de 1965- la subcomisión plenaria mixta dio forma definitiva a la estructura del texto revisado. En una nueva reunión, ahora de la Comisión mixta -última responsable del texto, conformada por la Comisión doctrinal, presidida por Alfredo Ottaviani, y la Comisión de apostolado laico, presidida por Fernando Cento, cada una de ellas con 30 miembros, más 7 obispos sumados provenientes “del así llamado 'tercer mundo’ y de regiones que están bajo el régimen comunista” (AS IV, 1, 520)- se concretó la última revisión general del esquema de Ariccia. Con una carta del 4 de mayo de 1965 los cardenales Cento y Ottaviani enviaron a Pericle Felici, secretario general del Concilio, el texto finalizado para ser presentado a la Comisión de Coordinación de los trabajos conciliares (AS V, 3, 222-282). Dicha Comisión sesionó el día 11 de mayo de 1965 y, después de un amplio debate, decidió que el texto podía ser enviado a los padres conciliares para su tratamiento en el cuarto período a iniciarse en septiembre de ese año.

La reunión del 11 de mayo tiene especial interés debido a un hecho particular: el debate entre varios de los miembros de la comisión sobre aspectos sustantivos del documento (AS V, 3, 302-304). La reunión testimonia los primeros problemas del nuevo título del Schema XIII, Constitutio pastoralis, y, con él, del conjunto del esquema y de algunas de sus peculiaridades. La mayoría de los participantes se manifestaron muy favorablemente sobre el esquema, pero hubo importantes opiniones contrarias. El secretario de estado vaticano, Amleto Cicognani afirmó que había que "buscar una manera de no involucrar a la Iglesia en cuestiones aún debatidas y de solución incierta" y, por lo tanto, propuso "no decir Constitutio, sino Litterae o Declaratio" del Concilio al mundo. 
El acta de la reunión consigna que esa propuesta "no es compartida por muchos" de los presentes (AS V, 3, 302). Por motivos análogos, Felici expresó su insatisfacción con el texto. De allí su principal conclusión: "Primero es necesario establecer claramente la cualificación que se quiere dar al documento". Proponía excluir el término Constitutio, incluso "si aparece añadido el adjetivo pastoralis, dice siempre algo extremadamente vinculante sobre el plano doctrinal" (AS V, 3, 303).

Distante ya de la mano de sus redactores, el texto comenzaba el camino de su tratamiento con la fijación del orden de trabajo de las sesiones del cuarto período (AS V, 3, 332-333). El título Constitutio pastoralis recibió pocos días después, el 20 de mayo de 1965, la explícita aprobación de Pablo VI en una audiencia con Pierre Haubtmann, teólogo francés, colaborador desde noviembre de 1964 del obispo Emilio Guano en la redacción del Schema XIII. Allí el Papa, aparentemente relativizando la importancia de las oposiciones, aceptó el título de Constitución pastoral refiriendo a lo decidido en la Comisión de coordinación donde, a pesar de las diferencias, se había aceptado finalmente. El 24 de mayo, Pablo vi firmó la autorización para el envío del documento a los padres conciliares ${ }^{7}$.

\section{PRESENTACIÓN DEL ESQUEMA EN EL AULA CONCILIAR: SEPTIEMBRE DE 1965}

La discusión en el aula conciliar del texto presentado el 21 de septiembre se extendió hasta el 8 de octubre. Las actas conservan el Schema (AS IV, 1, 435516), la Relatio generalis y las Relationes particulares incorporadas al texto enviado previamente a los obispos (AS IV, 1, 517-552) y la Relatio generalis de Gabriel Garrone, expuesta en el aula conciliar ese día inicial (AS IV, 1, 553-559). Se cuentan, además -incluso en volúmenes sucesivos- aproximadamente unas 550 intervenciones orales y escritas.

Garrone inicia su informe poniendo de relieve la complejidad del trabajo de redacción después de los debates de la tercera sesión del Concilio. Una tarea "ardua" que, ante todo, vincula al desafío que presenta la misma "materia", que incluso no estaba claramente definida y, en segundo lugar, un trabajo "arduo también en razón de la forma", dada la finalidad de los destinatarios que representaba algo "nuevo en la tradición conciliar" (AS IV, 1, 553). A su juicio,

\footnotetext{
${ }^{7}$ Una narración detallada del proceso entre el mes de noviembre de 1964, en que finaliza el primer debate sobre el Schema XIII completo, y el inicio de las congregaciones generales de 1965, lo ofrece G. TuRBAnTI, Un Concilio per il mondo moderno. La redazione della costituzione pastorale Gaudium et spes del Vaticano II (Il Mulino, Bologna 2000) 471-613.
} 
por tanto, era necesario tener presente, ante todo, la "complejidad de la materia" y la "diversidad de destinatarios".

La división del texto es "simple y clara en dos partes, después de la introducción descriptiva", argumenta. La primera, "de orden más teórica", define la relación en general de la Iglesia al mundo; la segunda, "más práctica", presenta los diversos aspectos de la actividad humana. Ellas están precedidas, como "los Padres lo postularon expresamente", por un texto inicial acerca de la "condición humana actual". En cuanto a su contenido, como lo propusieron igualmente muchos padres conciliares, se trata de una "antropología cristiana como elemento esencial". En cuanto al "modo de hablar", Garrone advierte que las "dificultades no eran menores." Destinado a todos los hombres y mujeres, "aquí, más que en cualquier otro lugar nos urge la intención y vocación del Concilio definida por Juan XXIII". En ese contexto Garrone justifica la elección del título de Constitutio pastoralis que determina "la cualidad teológica de este texto". A su juicio, el título "manifiesta lo que pretendemos"; "elegidos los destinatarios" hay que ser coherentes con dicha elección, argumenta.

El asunto acerca de los destinatarios, precisamente, es clave también en la relatio generalis que acompañaba el esquema. El tema ha tenido un "debate largo y difícil" en la comisión redactora, las posiciones de los padres conciliares al respecto han recibido un "atento estudio". Este estudio metódicamente conducido no deja dudas que el deseo de la mayoría de los obispos es que el esquema dirija su palabra "ad universos homines sine ulla exceptione". Claro que, añade inmediatamente, esta decisión tiene consecuencias importantes en el "estilo del esquema", en lo que se refiere al "modo de proceder" (AS IV, 1, 521-522).

"Acerca de la cualificación del documento" la relatio generalis afirma que "Constitutio pastoralis es el título más apto". La finalidad principal del esquema no es "ofrecer doctrina directamente", sino poner de relieve y concretar las "aplicaciones a las condiciones de nuestro tiempo" y formular "conclusiones pastorales". No puede ser calificado como un "decreto", porque carece de "prescripciones". La importancia del esquema se expresa bien con la palabra constitutio. Y una razón para advertir la conveniencia del título, observa, es "por oposición al de 'Constitución dogmática', es decir el De Ecclesia (Lumen gentium)" (AS IV , 1, 521). Pero la relatio argumenta de un modo algo impreciso: por la naturaleza "esencialmente pastoral del texto" no se requiere "un debate con tanto rigor de cada una de sus palabras", como se debe hacer en "asuntos estrictamente dogmáticos".

Se trata de una formulación provisoria, muy imperfecta, que da más cuenta de lo que el texto por "naturaleza" o rasgos característicos (indole) no es, que por una caracterización precisa de su novedad. Por ejemplo, no hay una 
problematización del concepto de "doctrina"; la idea de "pastoral" aparece asimilada con la práctica eclesial; la relación entre ambas es unidireccional: se plantea solo en términos de "aplicación".

También el "estilo" necesita explicaciones. La relatio generalis sostiene que numerosos padres conciliares desean un "estilo directo, simple, no demasiado eclesiástico o exhortativo, pastoral, heurístico, y en cuando fuera posible, acomodado a todas las personas". Igualmente ellos solicitan que se evite un estilo polémico o de condenación. Estas demandas, argumenta claramente, "no se oponen de ningún modo" a la solicitud de los mismos obispos acerca de que el esquema debe estar basado sobre "fundamentos teológicos, cristológicos, claros, firmes". Se espera que "todo el esquema" posea un "estilo sui generis", doctrinalmente sustentable, "pero acomodado al modo de hablar de las personas comunes". Tanto a los padres conciliares como a los laicos/as participantes en el trabajo, argumenta la relatio, les agradó el estilo del nuevo esquema que pone en relación realidades concretas con puntos doctrinales (AS IV , 1, 522-523).

La relatio generalis también dedica unos párrafos a lo que llama "finalidad y modo de proceder". Afirma que el "objetivo del esquema aparece óptimamente enunciado por un padre: reflejar la esperanza y la preocupación (en sentido de solicitud) por el hombre moderno, y mostrar una Iglesia tanto trascendente como también dirigida al servicio de los hombres [y mujeres]. Esta afirmación se adecua claramente al deseo de muchos padres", concluye. De allí que justifique la forma de proceder: iniciar con los hechos y las verdades que la mayoría de las personas admiten, incluso las no creyentes, para conducirlas "paulatinamente" a la "manifestación de toda la verdad revelada". La relatio afirma que solo pocos obispos preferían comenzar por la verdad revelada. En particular, se destaca que en los tres primeros capítulos de la primera parte el tratamiento se inicia con las "verdades y problemas" que atañen a todas las personas y que, cuando es posible, "se exponen de modo bíblico". El procedimiento que se verifica es "a partir de las cosas más conocidas hasta las manifestaciones de las verdades más altas de la fe cristiana", que se condensan en la persona del Verbo encarnado (AS IV, 1, 524).

Sobre la Expositio introductiva, que es la "parte nueva" del texto de 1965, afirma que fue compuesta en respuesta al pedido de múltiples obispos que demandaban un "modo de decir histórico, dinámico, intuitivo". Añade dos datos que son frutos de los debates de 1964: reconoce la labor de la subcomisión De signis temporum -que prestó especial atención a información no solo europeo-occidental- y considera el aporte de laicos/as que colaboraron de múltiples maneras. Al respecto es útil la Relatio pro "Expositione introductive" de Marcos McGrath, presidente de dicha subcomisión quien el 23 de septiembre (AS IV , 2, 391-394) le explica a la asamblea las "razones, forma y 
elementos principales" de esa introducción incluida a partir de la decisión tomada en noviembre de 1964, luego de los debates del tercer período conciliar. Este modo de proceder y de hablar (sive in methodo procedendi sive in modo loquendi) ofrece una descripción de "la situación del mundo actual" que colabora al "inicio más fácil y sincero" del objetivo que se persigue: "el diálogo con el mundo". Es lo que "autores idóneos" diagnostican como aspectos principales del mundo de hoy. No es una descripción exhaustiva, argumenta, tampoco es objetivamente diversa bajo el aspecto fenomenológico en comparación a otras descripciones de la situación del mundo que realizan organizaciones internacionales.

En ese contexto, McGrath formula la siguiente frase con la que explicita la conciencia general de una novedad en un documento conciliar y en una metodología: "Patet quod methodus haec aliquid novum est in documento conciliari: sed ipsum documentum nostrum est principalis novitas et novam exigit methodum" (AS IV, 2, 391). La novedad, no obstante, no aparece allí muy bien precisada. Acude a dos ejemplos magisteriales: Rerum novarum, donde se verifican "considerationes eorum de rerum novarum conditione, sive in re sociali, sive in aliis rebus"; y Ecclesiam suam en la que, dicho de un modo general, "se invita a un diálogo con el mundo". En ese camino se sitúa la Constitución: "In hac via iam satis aperta Sacra Synodus cum fiducia intrat, et quidem iam intravit” (AS IV, 2, 391).

Resulta claro en estas reflexiones que, para McGrath, los signos de los tiempos -si bien esta categoría fue excluida en esta versión del esquema- son comprendidos de un modo (unilateralmente) fenomenológico-sociológico, problemas que afronta la humanidad y que caracterizan una época, como se había explicitado también en los debates de 1964. Un doble nivel, una densidad teológica de los acontecimientos referidos y una perspectiva bíblica de la categoría están fuera de su consideración explícita. Igualmente, la relación entre esta exposición introductoria más descriptiva y las partes siguientes más doctrinales -ese "tránsito"- no tiene un análisis más preciso que su simple constatación y vinculación genérica. Sí se afirma que "el esquema ilustra los problemas a la luz del Evangelio" (AS IV, 2, 393). En cualquier caso, el significado de la inclusión de la expositio introductiva no puede minusvalorarse: con ella el esquema ver-juzgar-obrar caracteriza definitivamente la estructura global del documento. Los pasajes más detallados -dedicados al análisis de la

8 "De hac brevi descriptione schema immediate transit ad expositionem doctrinalem quae primam partem schematis constituit" (AS IV, 2, 392). Como en los debates de 1964, en varias exposiciones de 1965 se corrobora que la posición de McGrath acerca del sentido (unilateralmente) fenomenológico de los signos de los tiempos gozaba de consenso. Cf. las intervenciones de Agnello Rossi (San Pablo, Brasil), en nombre de 92 obispos brasileros (AS IV, 2, 462); Alfred Bengsch, arzobispo de Berlín (AS IV, 2, 655); Achille Liénart, obispo de Lille, Francia (AS IV , 3, 509); etc. 
situación- no son ya parte del tratamiento más dogmático, sino que adquieren un espacio propio, independiente, que precede a la primera parte del texto'.

Más allá de las expresiones precisas, la relatio generalis y las observaciones de Garrone y McGrath son muy significativas. Plantean temas que, en clara diferencia con los otros textos conciliares, reflejan la novedad del documento, evidente para todos los actores, sin excepción: acerca del título, la cualificación del documento, los destinatarios, el "estilo", la finalidad y el modo de proceder. Se trata de dimensiones intrínsecamente relacionadas, que requieren una adecuada comprensión para delinear el objetivo del proyecto. En la conciencia explícita de los padres conciliares -a favor y en contra- se lidiaba con una nueva materia, nuevos destinatarios, nuevo estilo, nueva forma de proceder, todo ello condensado en un nuevo título. Junto a los enormes desafíos referidos a los temas específicos de matrimonio y familia, cultura, vida económico-social, vida política, comunidad internacional, guerra y paz, estaba en debate el conjunto de un proyecto que aparecía como esencial al objetivo conciliar de Juan XXIII.

El 23 de septiembre se cerró el debate sobre el esquema en general con la aprobación del texto, en el sentido que se admitía el paso a la discusión en particular. De 2157 obispos votantes, hubo 2111 placet, 44 non-placet, solo un padre conciliar votó iuxta modum, y hubo uno nulo (AS IV, 2, 403).

\section{AlgUNAS OPINIONES GENERALES SOBRE EL ESQUEMA}

Es claro que el esquema de conjunto -particularmente el llamado estilo pastoral- agradó a la mayoría de los padres conciliares, pese a todas las limitaciones que no podían ocultarse. Los ejemplos podrían multiplicarse con facilidad. En su intervención escrita Gérard Huyghe, obispo de Arras, Francia, afirma que "en general, me gusta mucho este esquema, especialmente en su primera parte. Aprecio lo difícil que es abrazar un tema inmenso en unas pocas páginas, para expresar, por primera vez en la historia de la Iglesia, el interés que ésta tiene por los problemas del mundo, y hacerlo en un estilo que agrade a teólogos y no teólogos, creyentes y aquellos que no comparten nuestra fe" (AS IV, 2, 768). Maxim Hermaniuk, arzobispo de Winnipeg, Canadá, para los ucranianos expresa, igualmente, que le gusta el "estilo pastoral del esquema", la claridad de las ideas y la simplicidad de las expresiones (AS IV, 2, 51). Laurean

\footnotetext{
${ }^{9} \mathrm{La}$ inserción de esa introducción se debe a una sugerencia de Gérard Philips en las reuniones de la comisión mixta (teológica y laicado) de abril de 1965. De esas reuniones proviene también el título constitutio pastoralis, aunque en este caso no es posible precisar el autor. Cf. G. Turbanti, Un Concilio per il mondo moderno, 581; H.-J. SANDER, "Theologischer Kommentar zur Pastoralkonstitution Gaudium et spes", en P. HÜNERMANN - B. J. Hilberath (ed.), Herders Theologischer Kommentar zum Zweiten V atikanischen Konzil. Band 4 (Herder, Freiburg i.Br.: 2005) 581-886, 644ss.
} 
Rugambwa, entonces obispo de Bukoba, Tanganica, parte actual de Tanzania, también manifiesta un juicio muy positivo sobre el texto, sobre los signos de los tiempos, etc. Solo demanda más atención a las problemáticas internacionales, incluso a la específica situación decolonial del continente africano (AS IV, 2, 366-368). También el obispo de Saint-Boniface, Canadá, Maurice Baudoux, alaba el estilo directo, constructivo, positivo en relación con el mundo (AS IV, 2, 374). Análogamente se expresa Paul Richaud, arzobispo de Bordeaux, Francia. El esquema "manifiesta un verdadero equilibrio y una sana profundidad en la doctrina", "útiles proposiciones en asuntos concretos", conforme a las observaciones de los padres conciliares en el período anterior (AS IV , 2, 431). En el mismo sentido, casi con las mismas palabras, se expresa Lorenz Jaeger, arzobispo de Paderborn, Alemania (AS IV, 1, 575). Endre Hamvas, obispo de Kalocsa, quien habla en nombre de todos los obispos de Hungría, también emite un juicio muy positivo sobre el documento y lo califica como la "Carta Magna del Concilio Vaticano II" (AS IV, 2, 761).

Sin desconocer limitaciones, también la nueva exposición introductoria recogió muchas opiniones favorables. En un texto muy bien preparado, Sergio Méndez Arceo, obispo de Cuernavaca, México, en nombre de varios obispos latinoamericanos, alaba la expositio introductiva -su tono sociológico-, aunque reclama una complejización de la antropología expuesta, particularmente, en lo que llama la "revolutionem psychoanalyticam, que no es menor a la revolución técnica". Y agrega: "Genialis adinventio Sigismundi Freud similis aestimanda est adinventionibus Copernici vel Darwin" (AS IV, 2, 626).

Naturalmente, no faltaron apreciaciones negativas más o menos severas. Un testimonio crítico muy significativo está expresado por Joseph Frings, arzobispo de Colonia, Alemania, a quien asesoraba el joven teólogo Joseph Ratzinger. Junto a las observaciones repetidas por muchos otros obispos acerca de la insuficiencia de algunos conceptos clave, como la noción de pueblo de Dios o de mundo, el cardenal alemán cuestiona con severidad la finalidad del esquema tal como está formulada:

Hay una peligrosísima confusión ente el progreso humano -motivo por el cual se dice que se ha instituido el diálogo [entre Iglesia y mundo]- y la salvación divina que se obtiene por la obediencia de la fe. No es de admirar que esta confusión impregne todo el esquema, una vez que su finalidad es presentada tan confusamente (AS IV, 2, 405-406).

También el cardenal de Génova, Italia, Giuseppe Siri, con una reacción previsible, refleja una insatisfacción de raíz: "El esbozo de la Constitución Pastoral de Ecclesia in mundo huius temporis deja profundamente perplejo e intimidado no por una sola razón" (AS IV, 2, 25). 


\section{CUALIFICACIÓN DEL ESQUEMA: EL TÍTULO CONSTITUTIO PASTORALIS}

Una primera constatación que puede hacerse -en consonancia con la observación recién expresada- refiere al carácter transversal, desde el punto de vista ideológico, de las objeciones contra dicho título. Algunos ejemplos. Lorenzo de Proença Sigaud, obispo de Diamantina, Brasil, expresa múltiples consideraciones extremadamente críticas sobre el esquema que pueden resumirse en la peculiar frase final de su intervención: "Procuremos que el esquema nuestro no sea la Carta Magna del paganismo moderno bajo el aspecto de la santificación y sacralización del mundo" (AS IV, 2, 50) ${ }^{10}$. Con relación al título realiza su análisis, como muchos otros actores, a partir de la idea de constitución: "Constitutio est enim lex fundamentalis in aliqua re". Por el contrario, el documento en debate no puede llamarse "ley", ni por parte de su materia, puesto que el objeto de tratamiento no pertenece de ningún modo a una definición de asuntos de fe o moral, ni por sus destinatarios, puesto que los no bautizados "no están sujetos a la autoridad de la Iglesia"; no es ni lex credendi, ni lex agendi. Su conclusión es precisa: "Si autem non est lex, a fortiori non est "Constitutio»". De allí su propuesta: "Por tanto, que se cambie esta palabra, y se diga Mensaje, Carta, Epístola o alguna otra palabra" (AS IV, 2, 48).

En una posición muy diferente de cara al esquema a lo largo de toda la historia de su redacción, Karol Wojtyla, arzobispo de Cracovia, sin proponer un nuevo título advierte la dificultad: "Me parece más una consideración que una constitución". En una constitución conciliar se establece algo que refiere principalmente a lo doctrinal. "En nuestro esquema más bien se propone cierta visión de ideas para considerarlas en la teoría y en la praxis" (AS IV, 2, 660). Como se ve, los interrogantes acerca de lo adecuado de su título no correspondían solo a una parte del arco ideológico.

Una manera de verificar la importancia del asunto a los ojos de los actores lo representa la toma de posición por parte de conferencias episcopales enteras. En una breve intervención escrita, la conferencia italiana manifestó: “Conferentia Episcopalis Italiae postulat unanimiter ut titulus schematis XIII sit non Constitutio Pastoralis sed Declaratio Pastoralis. Ita magis respondere videtur suo fine suaque natura et materia" (AS IV , 2, 901). Aquí se propone otro título, Declaratio, a los ya citados de Sigaud, y muy repetidos, Nuntius, Litterae, Epistola. Se anota, siquiera brevemente, su motivo: la correspondencia con su fin, su naturaleza y materia. Por el contrario, la conferencia episcopal de Zambia expresó un juicio positivo

\footnotetext{
${ }^{10} \mathrm{~L}$. de Proença Sigaud y Marcel Lefebvre representan, quizás, las críticas más agresivas contra el documento conciliar. La descalificación de Lefebvre es global, refiere a todo el contenido, y también radical: se trata, a su juicio, de una "doctrina nueva", que en diversos lugares abiertamente contradice la doctrina tradicional de la Iglesia (AS IV, 2, 781).
} 
sobre el documento, incluido el título de constitución pastoral (AS IV, 2, 938941).

Varios obispos de Estados Unidos, también con una intervención escrita, proponen que el documento no lleve ese título, sino "uno más congruo con las materias tratadas". Tales títulos pueden ser "Epistula Pastoralis", o bien, "Litterae Synodales", o "Nuntius solemnis Concili?" (AS IV, 2, 893). Otro grupo conformado por 27 obispos de distintos países hace una solicitud análoga. Uno de los argumentos formulados es algo diverso: las personas de nuestro tiempo "a las cuales este documento se dirige, simplemente no entienden la palabra constitutio. El significado del documento debe ser claro para todos, también en el título". Proponen uno nuevo: "Allocutio Concilii Oecumenici ad homines huius temporis, vel aliud simile" (AS IV, 2, 893).

El argumento recién referido también aparece en intervenciones individuales. El ucraniano Atanasij Hryhor Welykyj, Superior general de la Orden de San Josafat, propone el cambio a "Litterae Synodales (vel conciliares) de Ecclesia in mundo huius temporis", pero no por un motivo crítico con el documento, sino atendiendo precisamente a los destinatarios, también a la naturaleza de las enseñanzas que ofrece, su forma y estilo. Argumenta que si se propone un diálogo con destinatarios tan variados es mejor no ofrecer una constitución, es una "pésima" señal presentar una "constitución unilateral"; se adecua más una carta sinodal (AS IV, 2, 874-886). En parte, Bruno Wechner, auxiliar de Innsbruck, Austria, sin con ello expresar una crítica al documento, argumenta en esa dirección: sugiere cambiar el título substituyéndolo por el de Litterae conciliares. "Esta nueva denominación se corresponde mejor con el contenido del esquema e invita más al diálogo, que es lo que se intenta." (AS IV, 2, 870-871).

No hay duda que el argumento más repetido contra el título reside en la idea que los padres conciliares poseen acerca de la naturaleza de una constitución conciliar; lo que ella es, lo que ella no es. A veces esa propuesta se formula brevemente. Por ejemplo, Raúl Zambrano Camader, obispo de Facatavitá, Colombia, propone agregar al título la palabra nuntium. El argumento: "Propter implicationes iuridicas verbi "Constitutio" (AS IV, 2, 890).

En una intervención muy crítica sobre el texto -que incluye múltiples aspectos- Luigi Carli, obispo de Segni, Italia, habla de "slogans" no adecuados para un documento conciliar y propone otro título. Por varios motivos, juzga que debe cambiarse a este nuevo: "Expositio pastoralis de condicione Ecclesiae in mundo huius temporis". Constitutio se da como lex credendi en asuntos dogmáticos, decretum como lex agendi en asuntos de disciplina. Por el contrario, aquí se habla "en tono coloquial" (quasi colloquiando) de la "situación" de la Iglesia en el mundo actual. Carli justifica el nombre expositio por el hecho de que se dirige a 
no creyentes, posee un estilo pastoral más expositivo que constitucional o de decreto, no es exigible un rigor detallado para las palabras y proposiciones filosóficas y teológicas que se emplean (AS IV, 2, 688). Argumenta, además, utilizando las palabras del relator al presentar el documento a la asamblea: se trata de una "materia nueva". Por tanto, afirma, si se reconoce la novedad para explicar las dificultades que presenta la confección del documento, a fortiori, más aún ella debe tenerse en cuenta en orden a clarificar su "cualificación teológica". A su juicio, este esquema "debe tener un grado teológico inferior al de la constitución de Ecclesia" (AS IV, 2, 696) ${ }^{11}$.

Casimiro Morcillo González, arzobispo de Madrid, opina que el "título es inadecuado" y ofrece las "razones" por las que propone "cambiarlo y substituirlo" (AS IV, 2, 378). En su intervención realiza un breve recorrido histórico acerca del uso de la palabra constitutio en los concilios, particularmente, el Vaticano I y también el Vaticano II. Ella refiere siempre a la transmisión de una "doctrina revelada", afirma. Y esto se corrobora también -argumenta el obispo español- en el lenguaje "técnico jurídico de nuestro tiempo" que, con constituciones o leyes constitucionales, refiere "solo a principios generales y estatutos fundamentales". Por el contrario, el esquema "asumido en conjunto, expone una cierta especie de teología de los valores y las realidades terrestres" y, con este laudable propósito, trasluce un "inevitable fenomenologismo". Si el documento quiere llamarse constitutio, "debe hablar de otro modo". Propone un nombre como el de libertate religiosa o algo semejante: "Declaratio Ecclesiae ad dialogum instituendum cum mundo buius temporis, aut Declaratio Ecclesiae ad mundum hodiernum" (AS IV, 2, 379).

En su intervención escrita João Batista Przyklenk, obispo de Januária, Minas Gerais, Brasil, recuerda las dificultades que varios padres conciliares pusieron para el título. Pero su argumentación revela otro acento. Acude también a los concilios Lateranenses y Vaticano I para afirmar que solo existen dos tipos semejantes: constitución y constitución dogmática. Advierte la novedad del esquema: "Sin duda nuestro esquema contiene muchas cosas nuevas, al menos el modo en que se expone la doctrina...". En ese contexto, destaca el valor de constitutio y por eso no le agradan los títulos que devalúan el valor del documento: Carta, Mensaje, Declaración, etc. Su propuesta, entonces: "Ergo maneat titulus Constitutionis simpliciter dictae, dematur vox pastoralis". Propone quitar el adjetivo pastoral porque no le agrada la devaluación que con él sufre el texto. $\mathrm{Su}$ preocupación de fondo es que el documento no tenga una cualificación inferior a la constitución sobre la liturgia (AS IV, 2, 806-810).

${ }^{11}$ La comparación con Lumen gentium aparece, además de en la relatio generalis, en otras varias intervenciones. Cf., por ejemplo, Luigi Faveri, obispo de Tivoli, Italia (AS IV, 3, 727). 


\section{El ADJETIVO PASTORAL, ¿AMBIGUO Y NO ESPECÍfICO?}

Precisamente sobre la noción análoga, o quizás equívoca, de pastoral, se expresan varios padres conciliares. Uno de los textos más concretos es el del cardenal Raúl Silva Henríquez, de Santiago, Chile. Le parece inadecuado el título de constitutio pastoralis. Distingue un doble sentido de la palabra pastoral. Por una parte, "describe la misma naturaleza de la misión de la jerarquía de la Iglesia", tal como se usa en el capítulo III de Lumen gentium. Refiere a todo lo que "pertenece a la misión de los apóstoles", ante todo, "el ministerio doctrinal". En este caso, opina, es evidente que aquí la palabra no significa una "oposición entre el fin pastoral y el fin doctrinal o dogmático". Por otra parte, la palabra pastoral también describe la "ordenación de la actividad apostólica, su apropiada organización”. Es claro, argumenta Silva, que el esquema no utiliza el término en este segundo sentido, "precisamente porque propone una verdadera doctrina" (AS, IV , 1, 565). Si lo utilizara en el primer sentido, sería apropiado, pero eso es lo que precisamente excluye la relatio generalis que acompaña al documento, argumenta. Silva alude aquí a la observación de la relatio, que sostiene que una razón para advertir la conveniencia de este título "Constitutio pastoralis" es "por oposición al de 'Constitución dogmática', es decir el De Ecclesia (Lumen gentium)" (AS IV, 1, 521). Como hemos recordado más arriba, la relatio advierte de un modo un poco impreciso: por la naturaleza "esencialmente pastoral del texto" no se requiere "un debate con tanto rigor de cada una de sus palabras", como se debe hacer "en asuntos estrictamente dogmáticos".

Por esto el cardenal chileno juzga inapropiada la denominación constitutio pastoralis: por una parte, es ambigua y, además, puede conducir a una "menor estimación del valor del documento". Por otra, en sentido amplio, la palabra pastoral corresponde a todos los textos conciliares, especialmente de este Concilio. Por tanto, no es una característica particular para atribuir a un determinado documento. Su propuesta es, entonces, clara: suprimir el adjetivo "pastoral", puesto que es "ambiguo y no específico" (AS IV, 1, 566), y titular el documento como Constitutio de Ecclesia in mundo buius temporis, de manera semejante al primer texto del Concilio: simplemente Constitutio de Sacra Liturgia. En otras palabras, afirma: "Clare agnoscatur ergo plura doctrinalia in nostro documento contineri; schema vocetur simpliciter "Constitutio de Ecclesia in mundo buius temporis»" $(\text { AS IV }, 1,566)^{12}$. Sobre la "cualificación teológica del esquema" Silva acude al criterio general expuesto para el De Ecclesia que, a su juicio, debe aplicarse para

\footnotetext{
12 Los obispos de Indonesia adhieren explícitamente a lo expuesto por Silva Henríquez: intervención escrita de Rudolph Staverman, vicario apostólico de Sukarnapura, Indonesia (AS IV, 2, 842).
} 
el conjunto y para cada enseñanza particular contenida en el texto (mentalidad del Concilio, materia tratada, criterios generales de interpretación, etc.).

Las dificultades con la palabra pastoral, no solo el binomio constituciónpastoral, se refleja, también, en la intervención de Carlos Maccari, obispo de Mondivì, Italia. Manifiesta que la "cualificación del documento", "no convence plenamente". Señala el problema de vincular el término pastoral al de constitución, que "tiene un sentido técnico", mientras que el primero está sujeto "a interpretaciones varias y diversas". Pregunta si para evitar ambigüedades e incertezas no sería más oportuno indicar claramente el carácter doctrinal de la constitución, aspecto que en la relatio generalis aparece de manera "genérica e insuficiente" (AS IV, 2, 787).

\section{6. "UN ESTILO MODERNO" - “MODUS LOQUENDI IN COLLOQUIO CUM MUNDO HODIERNO"}

Otra manera de argumentar, que destaca la novedad del documento y que impulsa a un cambio de título, puede recogerse en torno a la idea acerca del estilo del documento. John Whealon, arzobispo de Hartford, Connecticut, Estados Unidos, sugiere un cambio, pero no debido a una crítica particular, sino a su estilo: "Mejor es que este documento no sea una constitución, sino una alocución, epístola o algo similar”. Expresa, más precisamente, que el título que prefiere es Allocutio ad homines huius temporis. El estilo del documento es "como el estilo de una carta personal" (AS IV, 2, 887). Con un tono aprobatorio y positivo en relación al esquema Santo Quadri, obispo auxiliar de Pinerolo, Italia, afirma que el "estilo está ciertamente adaptado a las personas de nuestro tiempo", pero solicita que se añada expresamente en el texto mismo, y no solo en la relatio, "que la doctrina teológica es expuesta con un estilo moderno" (AS IV, 2, 817).

Paul Méouchi, patriarca maronita de Antioquía, ofrece una intervención muy rica y cuidada teológicamente que, además, refiere simultáneamente a varios de los aspectos destacados (estilo, destinatarios, título).

El estilo del Esquema, me parece, es el más adecuado, narrativo, claro, fácilmente comprensible, especialmente porque el texto está dirigido a todas las personas, incluso a aquellas que "están fuera" -y con buena razón- y que no están iniciadas en nuestro lenguaje teológico. Ya eso -estilo, destino e interés de la Iglesia por toda la humanidad, dialogando con ella y dándole su opinión sobre todos los problemas que le interesan y sobre las situaciones que la angustian- es altamente pastoral y permite dar a este texto el título de Constitutio pastoralis (AS IV, 2, 425). 
La idea de la novedad y peculiaridad del modo de hablar, ya consignada en la relatio generalis, aparece también en las intervenciones, pero, no pocas veces, con un sentido prevalentemente crítico. Léon-Étienne Duval, arzobispo de Algiers, Algeria, advierte que no obstante la pretensión claramente expresada acerca de dirigirse a todas las personas, "parece olvidarse muy a menudo esta intención". Ante todo, por "el empleo de un lenguaje ininteligible para los nocatólicos". Aporta ejemplos: "La referencia explícita a los misterios de la Trinidad, del Cuerpo místico, que no son deseables en un texto de este género", "el empleo de expresiones demasiado escolásticas", "por la referencia a opiniones teológicas perfectamente defendibles, pero que no gozan de la unanimidad en la Iglesia"; incluso advierte el uso de enunciados con un "tono grandilocuente, ampuloso". El Concilio "debe expresarse con simplicidad y también con firmeza", concluye (AS IV, 2, 673) ${ }^{13}$. En esta línea se sitúa también la intervención de Juan José Iriarte, obispo de Reconquista, Argentina (AS IV , 2, 773).

Una reflexión relativamente extensa, que incluye algunos ejemplos de Ecclesiam suam, ofrece Alberto Devoto, obispo de Goya, Argentina. A su juicio, "toda la primera parte del esquema debe ser concebida de un modo más evangélico, esto es, con aquella admirable simplicidad que se revela en las palabras del Señor, aunque Él hable sobre cuestiones trascendentales." Reclamando un mayor uso de la encíclica de Pablo VI, argumenta que ese modo más evangélico "se muestra más adecuado en el diálogo con el mundo moderno que el modo en el que se muestra cierta superioridad, por así decirlo: quizás un modo demasiado intelectual". Por el contrario, "la fuerza de su anuncio a las personas de nuestro tiempo no consiste en un modo solemne de hablar, sino en la misma verdad". De allí que proponga que, para la revisión del esquema, "se tenga en consideración esta simplicidad evangélica en la forma de hablar, para que las expresiones que no sean acordes a ella sean eliminadas o cambiadas" (AS IV, 2, 712).

Grégoire Haddad, auxiliar de Beirut, melquita griego, del Líbano, argumenta que el texto no parece ser coherente con la intención de presentarse como un ejercicio de diálogo con el mundo, no solo con el ámbito intra católico, y con su deseo de dirigirse a todo el género humano. "Parece dirigirse a los católicos para darles directivas pastorales o morales". Advierte una "ambigüedad permanente" que no satisface las exigencias del diálogo con todas las personas sin excepción, como se pretende. Esta limitación la señala también en relación "al objetivo, al método de abordaje y exposición, y al lenguaje empleado" (AS

${ }_{13} \mathrm{Al}$ modo de hablar muy escolástico refieren también varios obispos de Argelia en un texto común (AS IV, 2, 933). 
IV, 2, 750). Ofrece múltiples sugerencias puntuales para la corrección que, no obstante, no revisan la estructura global del documento.

En una línea próxima se sitúa la intervención escrita de Simon Hoà Nguyễn Văn Hiền, obispo de Đà Lạt, Vietnam. Alaba la universalidad de los destinatarios, pero pone de relieve que eso significa que es necesario prestar más atención a los términos y conceptos que se utilizan. "Unde si volumus ut alii nostram loquelam in sensu determinato, intelligant, necesse est utprincipaliores notiones modo conciso sed daro precisoque exponamus" (AS IV, 2, 800). Refiere a nociones tales como bien común, derecho (ius), officium, vida pública, etc.

\section{FORMA DE PROCEDER - ¿PRINCIPIOS PERMANENTES Y APLICACIONES PRÁCTICAS?}

La intervención de Juan Landázuri Ricketts, arzobispo de Lima, es interesante. Aunque expresa un juicio positivo del trabajo, presenta una crítica bastante radical y propone una profunda transformación del esquema. Es consciente de la novedad que implica la universalidad de los destinatarios, "el primer documento conciliar". A partir de allí observa una inconsistencia metodológica que, a su juicio, no satisface a ninguno de los dos públicos: ni a los creyentes, ni a las demás personas de buena voluntad. Si la Iglesia quiere hablar a todos los seres humanos "tenía dos caminos posibles": quitar del texto "todas las verdades que solo pueden conocerse a la luz de la fe", o bien, proponer toda la verdad divina, "si bien de modo acomodado a la mentalidad del hombre actual" (AS IV , 1, 562). El "primer método" es más bien "filosófico y humanista que teológico", perspectiva que está "menos en armonía" con un concilio ecuménico. El "otro método", argumenta, evita las dificultades, pero se restringe solo a católicos o cristianos. A su juicio, el esquema presentado "mezcla ambos métodos" y, entonces, no "satisface realmente" a ninguno de los destinatarios.

En el marco de ese comentario metodológico el cardenal peruano afronta también la cuestión del título: "Quizás la equivocación proviene del mismo concepto de constitución. En efecto el texto del esquema no es realmente ni debe ser una constitución, sino una simple proclamación (proclamatio) a todos los seres humanos". En esta declaración la Iglesia "no debe recurrir a argumentos filosóficos ni presentar categorías teológicas complicadas, sino anunciar el evangelio puro que la Iglesia tiene que predicar a todas las creaturas". A su juicio, las personas no esperan de la Iglesia "difíciles elucubraciones apoyadas sobre todo en la razón humana, sino más bien en la pura palabra de Dios que trasciende los siglos". De allí que demanda otro punto de partida y enfoque: "Ex Evangelio Christi et doctrina Ecclesiae systematice 
procedentes, haec problemata in luce fidei non solum multo profundius illustrabimus sed simul hominibus indicabimus verum vitae nostrae sensum qui ex sola morte et resurrectione Christi explicari potest" (AS IV, 1, 563). A partir de esta reflexión sugiere reformar "íntegramente la primera parte" y, de manera más breve, más "sobria y simple", presentar la doctrina católica acerca de la presencia de la Iglesia en el mundo y mostrar cómo ella debe permear como fermento a toda la humanidad. Luego, seguir con la segunda parte acerca de los problemas más urgentes exponiendo la materia de modo más conveniente y, sobre todo, "más teológico". Landázuri no refiere a la expositio introductiva.

Una postura más radical sobre el aspecto metodológico presenta Lorenzo de Proença Sigaud (Diamantina, Brasil). Advierte el abandono del "método y espíritu de la filosofía escolástica" y, por el contrario, la "adhesión al método y a los principios de la fenomenología actual". Esta forma de proceder no permite acceder a un conocimiento metafísico, a principios inmutables, "se niega el conocimiento de la naturaleza de las cosas", en esta perspectiva no existe "una verdad objetiva" (AS IV, 2, 48). De manera análoga se expresa el abad benedictino, Jean Prou OSB, superior general. Crítica al esquema por su "método llamado fenomenológico", que antepone el valor de la libertad, que convierte al magisterio eclesial en un asunto histórico. La Iglesia "incurre en un grave peligro asumiendo, incluso promoviendo, una filosofía completamente extraña a su tradición teológica" (AS IV, 2, 806).

Pero, por el contrario, no faltan juicios bien positivos sobre el método. Santo Quadri, obispo auxiliar de Pinerolo, Italia, expresa en su intervención escrita: "Como es opinión común, la forma de proceder debe partir de las cosas más simples del orden natural para llegar a las ideas más elevadas de la Revelación. Por consiguiente, toda la verdad cristiana se propone de una manera más inteligible" (AS IV, 2, 817). A Ignace Bedros XVI Batanian, Patriarca Catholicos de Cilicia, quien también propuso un cambio de título, le parece que "el método es de alabar", es decir, manifiesta lo adecuado de iniciar con una consideración sobre "las condiciones materiales y temporales, así como las diversas circunstancias" en las que viven las personas en orden a ayudarlas, sanarlas, elevarlas hacia Dios. Esta era la manera de obrar del Señor Jesús (ratio agendi Christi Domini) como se ve en sus sermones y parábolas; es el camino para llegar al conocimiento de Dios, como afirma Pablo a los romanos; es el camino que siguió Tomás de Aquino, por ejemplo, para hablar del número septenario de los sacramentos, procede a partir de las consideraciones de la vida humana natural, argumenta (AS IV, 2, 621).

Paul Méouchi, patriarca maronita de Antioquía, en su intervención ya citada más arriba, afirma también que "esta nueva parte descriptiva", la expositio introductiva, "es muy buena, pero incompleta" (AS IV, 2, 427). 
Si hemos hecho bien en partir de la existencia humana actual, no debemos entregarnos a la simple descripción sin iluminarla con la luz de Cristo. Describir es fácil, pero describir no resuelve el problema. Sin embargo, alabo el método, pero que, como cualquier método, tiene sus ventajas y desventajas. Se debe prestar atención aquí a las desventajas a las que se podría caer más fácilmente que con el método deductivo (AS IV, 2, 426).

Se alaba el método, se advierte su punto clave -iluminar la existencia con la luz de Cristo-, se expresa consciencia de los límites, se solicita el enriquecimiento teológico del momento iluminativo, gracias también a la teología oriental (resurrección de Cristo, teología del Espíritu Santo, antropología cristiana).

Franz König, arzobispo de Viena, advierte que el Concilio "con la elaboración de este documento ingresa a nuevos caminos en la historia de los concilios...". Se trata de un nuevo "tipo de doctrina conciliar" (AS IV, 2, 2627). En particular, sobre el método, König apunta la preocupación de que la descripción del mundo moderno realizada, que le parece acertada, pierda valor con rapidez. De allí su propuesta de insistir en lo que califica como un "principio fundamental" en la primera parte. Destaca la misión de la Iglesia en el discernimiento constante de los signos de los tiempos, necesario en nuevas situaciones. Se interroga acerca de qué manera "se llega a una correcta comprensión del mundo actual"; "cuáles son las cuestiones últimas que adquieren siempre nuevas formas" y que cada generación debe afrontar. Parece que el cardenal austríaco está demandando una criteriología que permita afrontar nuevas situaciones, más que detenerse en la descripción realizada que, por naturaleza, es pasajera. La exposición del cardenal austríaco representa un importante apoyo a la forma de proceder del documento ${ }^{14}$.

Aniceto Fernández, Maestro general de la orden de los predicadores, solicita atender a la distinción entre bienes naturales y sobrenaturales y, en ese contexto, pone de relieve cómo "para resolver los problemas concretos de este mundo no es suficiente la consideración teórica de los principios, sino el llegar en cuanto sea posible a aplicaciones prácticas en casos singulares" (AS IV, 2, 500). La tarea es doble: formulación de principios y aplicación práctica. La palabra "aplicación" aparece de manera repetida en las intervenciones de los obispos. Este tipo de jerarquización se observa nítidamente en el aporte de Franz Hengsbach, obispo de Essen, Alemania (AS IV, 3, 14).

José Rafael Pulido Méndez, obispo coadjutor de Mérida, Venezuela, expone la idea de que el vocablo constitutio refiere a algo estable, fundamental; pastoralis,

${ }^{14}$ Jaime Flores Martín, obispo de Babastro, España, alaba el método de la JOC como recomendable para la evangelización, pero sin relacionarlo con la estructura del documento (AS IV, 2, 724). 
a normas emanadas a partir de aquellos principios; y mundo buius temporis, dirige la mente a las cosas mutables y al decurso del tiempo cambiante (AS IV, 2, 810). A partir de esa clarificación afirma que, a su juicio, no hay una "suficiente distinción" entre los aspectos permanentes y las aplicaciones prácticas. Reclama corregir esa "deficiencia". No parece contener una crítica al título, más bien una constatación de los dos polos - principios permanentes y aplicaciones prácticas- y la solicitud de una mejor distinción y articulación. De hecho, el obispo venezolano no demanda la revisión de la estructura, solo hace sugerencias menores a diversas expresiones, y tampoco pide un cambio de título. Con un acento más crítico Giuseppe Zaffonato, arzobispo de Udine, Italia, solicita una reafirmación de los "principios fundamentales" y pide evitar el descenso a cuestiones más concretas que, en su opinión, se podrían dejar a una instancia posconciliar (AS IV, 2, 888-890).

Alfred Bengsch, arzobispo de Berlín, quien era muy crítico con el esquema, advierte aquí el problema del documento en la nueva materia que se trata, que hace que no pueda compararse este texto con ninguna otra constitución: "Intima ratio totius difficultatis in eo est, ut evidenter in hoc schemate novam materiam attingimus, quae non materiae aliarum constitutionum aequiparanda est" (AS IV, 2, 654). El problema está en la "misma concepción del esquema" que, en su opinión, puede plantearse exactamente con esta formulación: "Quomodo Concilium dialogum cum mundo hodierno instituere potest?" Este diálogo, argumenta, "es una obra nueva, recién iniciada y en continuo perfeccionamiento", de allí que no pueda afrontarse como una constitución dogmática. Dos aspectos destacan a partir de esta argumentación. Por una parte, el esquema debe ser "considerado como una declaratio" (AS IV, 2, 654); por otra, se tratan cuestiones que exigen la formulación de principios generales, cuya respuesta a situaciones concretas no es siempre posible -sea por las diversas condiciones en las naciones, sea por la evolución y estudios no acabados-. Una preocupación análoga a la de Bengsch aparece en Gerardus Henricus de Vet, obispo de Breda, Holanda, en una intervención en nombre de todos los obispos holandeses: la dificultad de la relación de la doctrina cristiana con las "situaciones mudables y fluctuantes", cómo precisar la "obligatoriedad moral" de una enseñanza. Lo formula explícitamente como el desafío de la "historicidad" (AS IV, 2, 710-711). Esta preocupación, por no poder precisar los juicios en las variables situaciones diversas y cambiantes, se refleja también en las intervenciones de Antonio Fustella, obispo de Saluzzo, Italia (AS IV, 2, 738) y Pedro Cantero, arzobispo de Zaragoza (AS IV, 2, 441). 


\section{UNA INTERVENCIÓN PARTICULAR: JULIUS DÖPFNER EN NOMBRE DE LOS OBISPOS ALEMANES}

La exposición del cardenal Döpfner, arzobispo de Múnich, merece una atención especial. Ante todo, tiene particular relieve porque, en nombre de 91 padres alemanes y escandinavos, reflejó las profundas desconfianzas muy extendidas en obispos y teólogos alemanes. Afirma que el texto debe ser "esencialmente enmendado", que "todavía debe y puede ser perfeccionado sustancialmente en muchas cosas". No obstante, con un tono general positivo, plantea un juicio moderado sobre la forma de proceder del documento:

El esquema procede desde las preguntas concretas de los seres humanos de nuestro tiempo. Además, se propone, aunque no siempre con completo éxito, encontrar un modo de decir que sea realmente entendido por ellos y que los invite al diálogo. Este método debe ser completamente aprobado, incluso todavía llevado a cabo. (AS IV, 2, 28)

Sus observaciones de enmienda se concentran, más bien, en lo referido a lo doctrinal, en la antropología, el justo equilibrio y desarrollo de cada aspecto en ella, y la adecuada distinción natural-sobrenatural. La carencia de un desarrollo e integración del aspecto pecaminoso y el riesgo de un optimismo excesivo con promesas de solución, argumentos muy repetidos en múltiples padres conciliares, también se consignan.

Si el juicio moderadamente positivo de la forma de proceder hecho por Döpfner no puede opacarse, sobre todo atendiendo a las conversaciones sostenidas esas semanas con obispos y teólogos franceses y belgas, también se formula una pregunta de fondo. Entre los problemas aún no propuestos en el esquema con suficiente claridad anota: “¿Precisamente qué puede ofrecer la fe para iluminar y fortalecer al mundo? Sin duda, se revelan algunas cosas a partir de esta cuestión, pero no con la claridad que se espera de este texto" (AS IV, 2, 29). Döpfner reconoce que "por la novedad de la materia" es comprensible que se adviertan "imperfecciones". El texto "debe concederlo simple y sinceramente; y no será deshonroso para la Iglesia, sino un honor". Nuestro documento es un inicio del nuevo diálogo con el mundo, "y este inicio es bastante difícil", destaca con letra cursiva (AS IV, 2, 29).

A su intervención oral Döpfner añadió un texto escrito que, como es sabido, corresponde a la autoría de Karl Rahner (AS IV, 2, 31-33). Allí hay un tratamiento detenido de diversos aspectos que, naturalmente, superan en detalle y precisión las observaciones aportadas por la mayoría de los padres conciliares. Rahner demanda una fundamentación de la forma de proceder, no su abandono, aunque es verdad que las múltiples y repetidas observaciones críticas suyas a lo largo del proceso de redacción dejan ver que él hubiera 
preferido un tratamiento posconciliar de estos asuntos ${ }^{15}$. La solicitud de Döpfner -de considerar este texto solo como "un inicio del nuevo diálogo con el mundo" y de reconocer explícitamente sus limitaciones- debe interpretarse en esta línea. En todo caso, con esta intervención quedaba clara la postura del episcopado alemán, en nombre de quien Döpfner hablaba: no se opondrían a una aprobación y publicación del texto como un documento conciliar, aunque en septiembre-octubre de 1965 requería ulteriores -importantes- mejoras.

\section{REFLEXIONES FINALES}

Formulo aquí dos consideraciones finales. En un texto de 1967 Rahner reconoce que, a partir del lenguaje tradicional de la Iglesia y su magisterio, "no es fácil decir qué es propiamente una Constitución pastoral". El carácter de su propuesta allí desarrollada deja abierta "la cuestión acerca de qué hace

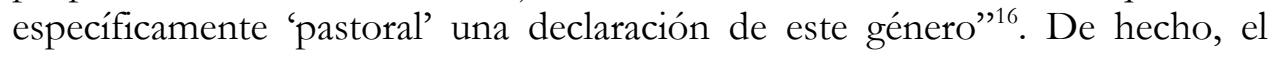
debate conciliar metodológico referido en esta contribución muestra la pluralidad de miradas sobre esta categoría clave: pastoral. A la pregunta por su significado -en sí misma como noción, en la utilización como adjetivo en el título y al caracterizar la forma de proceder- se verifican una variedad de opiniones. Las mismas indicaciones dadas por los responsables y redactores del esquema, como se ha mostrado, son muy genéricas. Parece que un importante número de padres conciliares comprendían el asunto en estos términos: por una parte, la doctrina refiere a la enseñanza teórica, más precisamente, a la formulación de principios generales; por otra, lo pastoral aparece identificado con la práctica, entendida como la aplicación de aquellos principios a realidades particulares situadas. Se trata de una arraigada separación de estos dos polos, que va desde el interior de la fe al exterior del mundo real, en una relación de superior-subordinado, pero no en la dirección inversa. Si se compara esta difundida conciencia de aquel momento con las reflexiones acerca de una pastoralización de la doctrina -tal como se encuentra en los planteos de Christoph Theobald, o con la comprensión de Hans-Joachim Sander acerca de una elipse con dos focos, que cuestiona la jerarquización doctrina-pastoral y que pone de relieve, más bien, la reciprocidad de esos dos polos que, congregados, ambos quedan transformados y en esa unión formulan propiamente una innovación- se advierte un arco de interpretaciones muy

\footnotetext{
${ }^{15}$ Un análisis más detallado de la posición de Rahner puede verse en C. SCHICKENDANTZ, "Un nuevo capítulo de epistemología teológico-pastoral”, Atualidade Teológica 58 (2018) 133-158, 139-148.

${ }^{16}$ K. RAHNER, "Zur theologischen Problematik einer 'Pastoralkonstitution"', en K. RAHnER, Sämtliche Werke. Das Zweite Vatikanum. Bd. 21/2, (Herder, Freiburg i.Br. 2013) 904-922, 904, 906.
} 
amplio. Estas consideraciones reflejan que en Gaudium et spes se encuentra (solo) una formulación inicial, destinada a madurar, pero que contiene, indudablemente, una auténtica novedad que lentamente se abre camino. Una constitución pastoral del magisterio conciliar, título inédito, estructurada en base al esquema ver-juzgar-actuar, simbolizado en la categoría de signos de los tiempos representa el inicio oficial de una innovación metodológica en el proceso de creer y argumentar, en la fe y la teología. Se trata de la transformación de un "orden lógico y teológico" (Congar) cuya comprensión y profundización es una tarea del tiempo posconciliar. Unas frases de Theobald visibilizan bien ese proceso: "El cambio decisivo, inaugurado por el Concilio, puede entenderse como la salida del 'paradigma dogmático' y la inauguración de un nuevo paradigma calificado por el término conciliar de "pastoralidad" 17. La relación entre doctrina e historia se sitúa en nuevos términos. La atención a los destinatarios -al contexto histórico-cultural- en el momento de elaborar el discurso es un factor primordial; un aspecto central y repetido en el debate conciliar como se ha verificado.

Con nuestra actual conciencia - educada con criterios de interculturalidad y del llamado giro decolonial- el proceso en desarrollo esbozado en estos testimonios de 1965 muestra un creciente reconocimiento de una de las perspectivas medulares en dicho giro: la relevancia reconocida al contexto cultural, a la localización, al lugar de enunciación, a la geopolítica del conocimiento. El debate conciliar evidencia múltiples intervenciones que, ayudadas por un incipiente método histórico-inductivo, pretenden enriquecer la comprensión de la realidad desde dos perspectivas convergentes: temas singulares a considerar y profundizar y una mayor internacionalización del análisis; ambas orientadas a hacer justicia a la complejidad y diversidad de las experiencias humanas, individuales y sociales, geográfica y temporalmente situadas, radicalmente afectadas por razones étnicas, de género y múltiples condiciones estructurales de variada condición. La importancia del "orden fenomenológico", según la expresión de Congar citada en la introducción, que presta atención especial a la condición humana en el mundo contemporáneo, revela de esta manera su significado epocal para que la fe y las teologías puedan afrontar, en mejores condiciones, nuestro mundo y sus desafíos.

${ }_{17}$ C. THEOBALD, "Mon itinéraire au pays de la théologie", Laval théologique et philosophique 68 (2012) 319-333, 331. 